\title{
Steps Towards a New Suburbia: The Benefits of Comprehensive Planning
}

Colin DRUKKER AND LISA JABUKa

Colin Drukker is a senior planner and project manager at The Planning

Center's Costa Mesa office in California, serving as project director for its efforts on suburban studies.

Lisa Jabuka is CRP (Cal

Poly San Luis Obispo) graduate. She is an associate planner at The Planning Center's Costa Mesa office in California, focusing on general plans and specific plans for private developers.
As noted by The Planning Center in the presentation to CRP design studios in 2006, because most residential growth in the US will continue to happen in the suburbs, we must concentrate our efforts in planning for better suburban development. The authors write about The Planning Center's philosophy towards providing for better communities and for sense of place in the suburbia, and they illustrate their discussion with three recent case-studies.

In the next forty-five years, America will need to house about one hundred million additional people. Much of this growth will take place in our suburbs. In the past, conventional suburbs were less the products of a reasoned approach to growth than expressions of blind faith in long-standing market forces. The result is sprawl, with all of its attendant ills: long commutes, excessive fuel consumption, pollution, and the proliferation of formless, lifeless communities. It is development without community; growth without purpose; expansion without a model for a sustainable future.

But, as we have learned from surveys and focus groups, Americans long for a sense of community, a livable environment for their families, access to nature, centers they can walk or bike to - features that most post-1950 suburban developments have failed to provide.

Creating true community in suburbia will be one of the most pressing challenges facing planners, developers, architects, and land use policymakers of the new generation. To meet that challenge successfully, we must consider strategies that address all of the moving parts that make up our communities. There is no panacea; there is no single land use policy or design construct that can be copied and pasted across the country to create great places to live. However, conversations on strategies for accommodating the coming growth have become increasingly polarized, partisan, and dominated by disputes over one or two issues.

At a fundamental level, a community can best be understood as an interaction of five critical elements -economic, environmental, physical, social, and governmental. This framework is broad and we recognize that many issues apply across many of the elements. As an example, affordable housing is as much a social as an economic concern. This interrelatedness makes a comprehensive discussion all the more important. Addressing all of the elements brings everyone to the table and prevents "silo solutions," which fix one problem but ignore related issues (Drukker, 2006: 3).

Instead, we ask that a more comprehensive approach be taken-a philosophy of planning, design, and development that aims to coordinate and improve all of the complex elements that make up a community. Addressing all five elements will facilitate the growth of a complete community that can accommodate our coming growth while maintaining and improving our quality of life.

For the past two years, The Planning Center, a multidisciplinary planning, urban design, and environmental firm headquartered in Costa Mesa, California, has been studying successful communities to better understand the fundamental elements of places in which people enjoy living. The ongoing study has resulted in two publications and over twenty detailed case studies of cities, towns, and communities throughout the United States. The most recent publication, Five Steps Towards a New Suburbia, published in October 2006, summarizes the five main elements intrinsic to building a complete community. 
In this article, we explore a range of different planning efforts through three case studies that exemplify the Five Steps model:

- Santa Ana, California: an infill project that uses flexible space as a response to changing market forces and a hydraulic parking lift system that efficiently uses available land on this small site;

- Woodlands, Texas: a master planned community that fosters social connections and equity through the integration of a range of housing types within each village; and

- Westlake, Ohio: a mixed-use town center that uses conditions of approval to guarantee a healthy mix of residential and commercial uses in each project phase.

Each example has been selected because it excels at incorporating one of the five steps in an especially creative way. The policies and planning efforts discussed in the following examples are extremely innovative, but they are also practical enough to be applied and implemented within other communities.

\section{ECONOMIC - Creating Flexible Places}

\section{West End Commercial Lofts in Santa Ana, California}

As market demands change over time, communities experience a flux of uses and dominant industries. Part of creating a sustainable community includes planning for this natural evolution by developing flexible built structures. Flexible spaces and buildings are defined as areas that can easily transition or convert from one use to another. This can be done through site planning and building design. Various techniques include versatile interior and exterior design, access that could be easily adjusted for public or private use, and the height of a building or space being open enough to house a range of different uses.

The flexibility of spaces is becoming increasingly important as many cities and communities incorporate mixed-use designations into zoning codes or individual projects. Ground-floor retail with office and residential located above is a traditional and ideal mixed-use concept, which works well when there is a market to support the ground-floor retail. However, it can be hard to predict exactly how much ground-floor retail will be sustainable, as this depends on the type of retail, project location, adjacent new retail projects, and phasing of new or infill residential within the project or within close proximity to the site.

The West End Commercial Lofts by Urban+West, a proposed project in Santa Ana, California, will be an example of a building planned for mixed use, but with flexible building design and development regulations that will allow its uses to transition if unsuccessful. Currently, the project is planned to include a six-story building with five floors of flats and ground-floor retail, but the building will be designed so that the uses could vary as a response to changing market conditions. Its design would potentially allow the building to be used for a mix of office, residential, and retail depending on which uses prove more viable at that location over time. The City of Santa Ana is employing a creative zoning
Figure 1

Artist's rendering of the West End Commercial Lofts in Santa Ana, CA.

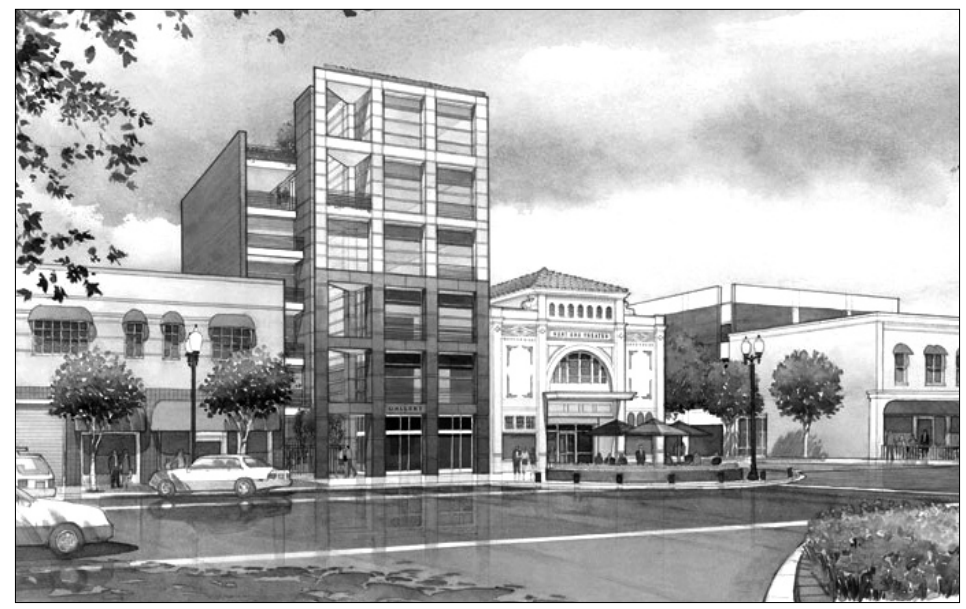


${ }^{1}$ Darin Schoolmeester, Principal, MVE Architects. 2006, October 10. Interview with Colin Drukker, The Planning Center. standard that will allow for the transition from residential to commercial use without requiring a permit. In order to check this progressive policy, the City regulates the zoning standard with a detailed list of permitted uses and operation standards.

When designing a flexible space, the functionality, compatibility, and accessibility of all potential uses must be considered. Darin Schoolmeester, a Principal at MVE Architects, comments that when creating flexible spaces it is imperative to, "be careful on how the space is used. Spaces suitable for retail must be public and exposed. This creates a unique edge that must relate the surrounding conditions and uses. Converting it to residential will not always work as that use requires a very different edge and environment - mostly. It is not always good to create an active edge when the demand is not there." 1

In order for the building to be used as either residential, office, or commercial, public parking must be either available in surrounding areas or built into the project. Schoolmeester notes that if the space is parked for residential and converts to retail there could be a significant parking problem; the only way this can work is if the project is sited in an area with a strong public parking plan. The West End Commercial Lofts project is able to avoid this potential pitfall, as it is located in Santa Ana's Downtown and Artist's Village and within walking distance of numerous public parking garages.

Along with creative design and zoning, this project also utilizes an innovative solution to meet the parking requirement on the land-constrained infill site. At approximately 40 feet wide, it would be difficult to achieve the turning radius necessary for subterranean parking, and surface parking is too inefficient. As a solution to this problem, parking for this project will use a German hydraulic lift system, which will cost approximately half the amount of subterranean parking and be an extremely efficient use of land. The lift system can hold up to eight cars, which is the required number of spaces for this project. Likened to a Rubik's Cube, the system uses nine trays, organized three wide by three high, to shuffle the stacked cars. It takes approximately 20 to 40 seconds for a car to be retrieved by the semi-automatic lift system (Taxin, 2006).

All aspects of the proposed West End Commercial Lofts embody a planning effort that accounts for the evolution of the area and markets over time. By considering long-range planning implications and building them into a current-planning project, the building is more likely to become a sustainable, usable, and economically viable structure for the City of Santa Ana.

\section{SOCIAL - Building Social Capital and Equity through Housing Variety}

\section{The Woodlands, Texas}

Social aspects of place are equally as important as design and physical form. Social infrastructure plays a large role in drawing residents to an area and should help engage all segments of a community in volunteer, recreational, spiritual, and educational events. It is this social fabric that allows residents to invest in a place. One technique to building a healthy social network within a City or community is to mix housing types of all size, tenure, and density, which works to create an inclusionary and connected social environment instead of one that is exclusionary and segregated.

As new communities develop and existing suburbs evolve, it is common to see the isolation of for-sale single-family residential housing in exclusive enclaves. Traditionally, single-family homes have been developed in mono-functional tracts, as the protection and preservation of these neighborhoods is promoted above all other land uses. This trend originates as a manifestation of the American Dream, 
which places great importance on owning a single-family detached home. Because it is seen as a supreme use, single-family residential is commonly developed separately from, so as not to be devalued by, different uses. The effects this has on the American landscape can be seen on zoning and land use maps in all areas of the country, represented as large uninterrupted blocks of single-shade yellow.

This separation between single family homes and all other uses can be harmful for a community, as it divides uses and people that can and should function together to form a community. Multiple types of housing are not only compatible, but complementary, and offering a variety of tenure, density, type, and size provides residents added choices. Additionally, it affords common amenities, schools, and roads of the same quality for all residents, regardless of home price or property tax collection, helping to erase the line between the haves and have-nots.

Over time, many communities have come to acknowledge that integrating multiple compatible uses, especially various types and tenures of housing, can result in community-wide benefits. Integrating different types of housing can facilitate social equity and add value to the entire neighborhood, by providing a true and interesting community fabric.

The Woodlands, a master planned community just north of Houston, has successfully integrated a wide variety of housing types. George Mitchell, founder of The Woodlands, had a vision for a community that would benefit people of all ages, socio-economic groups, races, and religions. His goal was to create a new community - not just a collection of subdivisions.

The vision helped dictate land use and organized the 25,000 acres into seven self-contained residential villages. Small neighborhoods in each village were each allocated for different types of housing, varying in tenure, density, and value. Additionally, subsidized housing is provided in all seven residential villages and located within walking distance to market rate units. This design and community structure allows for sharing of amenities, where all residents_-regardless of economic status-within the village enjoy the same schools, security, trails, ball-fields, playgrounds, and community pools. Because public schools typically receive some funding based on local property tax revenue, the blending of housing types helps to create educational equity and eliminate school busing.

Along with the will to implement it, The Woodlands was also graced with the means to fund the endeavor, courtesy of a $\$ 50$ million loan guarantee from the U.S. Department of Housing and Urban Development (HUD) (Galatas \& Barlow, 2004). The agreement with HUD required The Woodlands Corporation to provide low- and moderate-income housing and ensure equal housing opportunities to people of all races and ethnicity. During the development of the first villages, potential home builders were initially apprehensive to the mixing housing types of varied

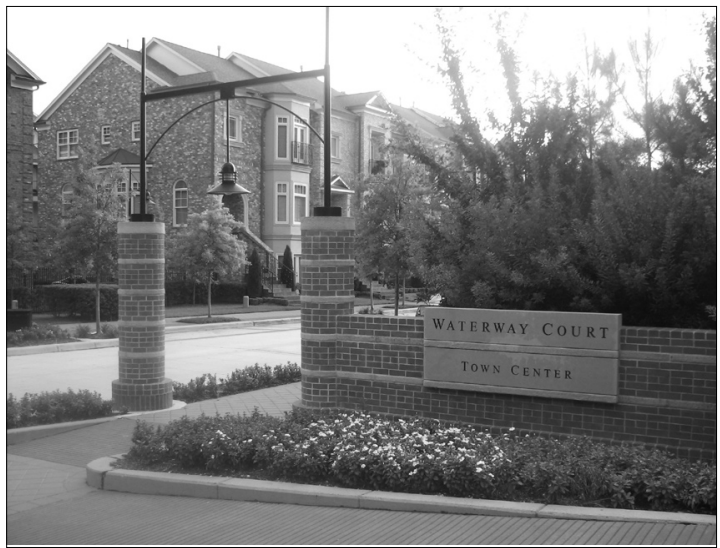

Figure 2

The Brownstones, one of the housing types in Woodlands, Houston TX.

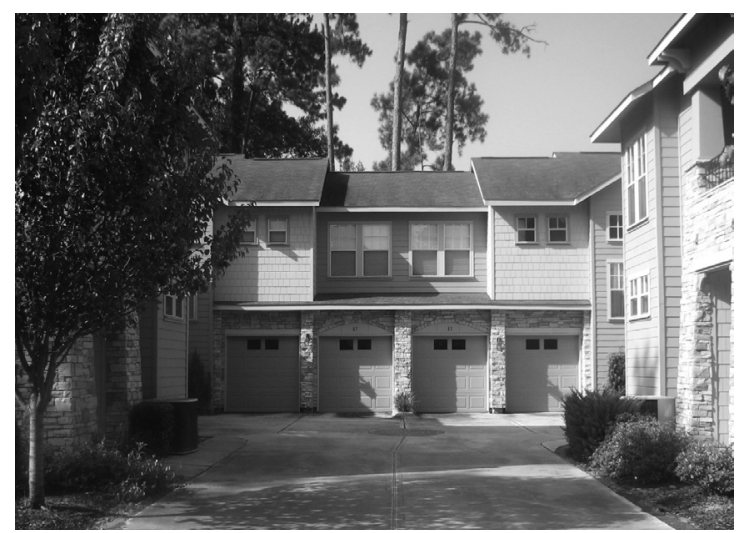

Figure 3

The motor-court, a housing types in Woodlands.

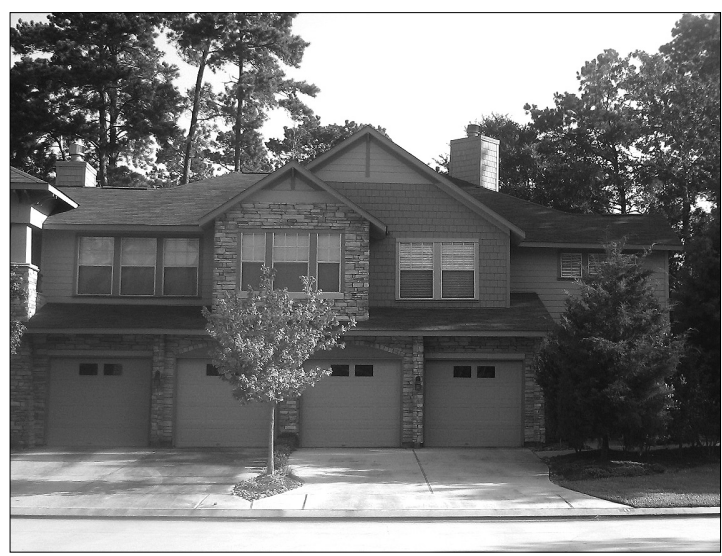

Figure 4

A multi-family building in Woodlands. 
2 Roger Galatas. 2006, October 6. Interview Planning Center. with Lisa Jabuka, The

tenure, density and cost within the same neighborhoods, but The Woodlands Operating Company held to its established vision and rules for development. Once the Woodlands had shown market success, builders embraced and supported the integration of all housing types

Roger Galatas, former chief executive officer of The Woodlands Operating Company, credits the success of the integrated housing not just to design but also to The Woodlands residents who 'buy into the vision.' According to Galatas, "Residents continue to support the inclusionary character of the Woodlands versus exclusionary (or gated) neighborhoods located elsewhere." 2 Galatas notes that the physical and social structure of the villages allows for tremendous opportunity for resident participation through volunteering because all members share in the success of the community.

\section{GOVERNMENT - Establishing Development Regulations for a Balanced Town Center}

Crocker Park in Westlake, Ohio

(Author Sam Newberg, Joe Urban, Inc., in conjunction with The Planning Center)

A flexible government structure along with creative land use regulations can help to create successful communities. To create a unique place, inventive and site-specific regulations should be established so that a place or city can develop in the way the area was originally envisioned. Crocker Park, a 1.7 million square-foot mixed-use town center located on 75 acres in Westlake, Ohio, a suburb of Cleveland, is an excellent example of a forward-thinking city government guiding a major suburban redevelopment project. The city worked with the developer, Stark Enterprises, to ensure that a balanced mixed-use town center was developed, and that Crocker Park was not dominated by disconnected blocks of commercial buildings.

Figure 5 Crocker Park,

Westlake, $\mathrm{OH}$. In spring time the developer places hundreds of potted plants along sidewalks to foster a lush garden feeling.

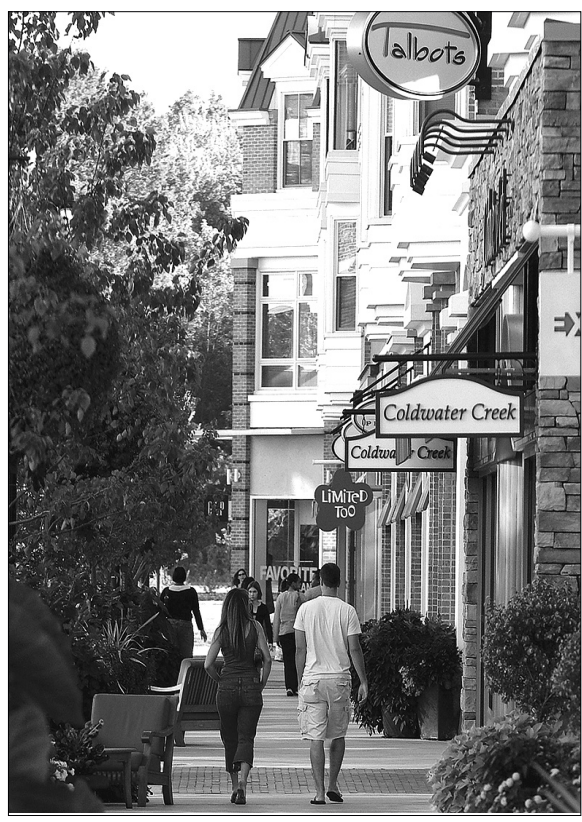

The concept for Crocker Park dates to the late 1990s, when the city of Westlake was deciding how to develop one of its few remaining commercial parcels. Although the upscale community had an underserved retail market, the city did not want to build "just another retail mall," and Stark Enterprises came forward with plans for a mixed-use town center. However, the city had an "ultra-Euclidian" zoning code, in which their planned unit development (PUD) did not allow for mixeduse development. In order to change the zoning of the site to allow for mixed-use development, a city-wide referendum was held in 2000. It passed, but not without controversy. Not all staff or elected officials were in favor of the project, and Stark Enterprises embarked on a door-to-door campaign to gain support from residents.

A few parts of the approvals process stand out among town centers in other cities across the country. Because they wanted Crocker Park to be a well-balanced mixed-use community, the city of Westlake negotiated in the PUD agreement that no more than 35 percent of the entire project's square footage can be retail, and that over 50 percent of the project must be residential; a rule that applied to all phases of development. The concurrent residential requirement is important because it provides a balance of uses throughout each phase of development. The city also requires that over 50 percent of the parking stalls at Crocker Park must be in structures or ramps. The developer exceeded that, with two-thirds of all parking located in a ramp or structure.

The project, designed by Street-Works, takes its inspiration from Mizner Park in Boca Raton, Florida and Santana Row in San Jose, California. From a design point of view, the project has a very strong pedestrian orientation. There are varied 
facades, wide sidewalks, extensive landscaping, benches, and an oversized chess set. Stores must follow strict design and signage requirements, and every new storefront exterior must be approved by the city. The project does not contain a single anchor tenant; the city and developer believe Crocker Park itself is the anchor. Some of the retailers and restaurants at Crocker Park include Barnes \& Noble, H \& M, Gap, Talbots, Coldwater Creek, and the Cheesecake Factory.

Residential apartments are located above retail stores in vertically mixed-use buildings. Additionally, "liner lofts" are being introduced at Crocker Park, consisting of townhomes built around the exterior of various parking ramps. The liner lofts are three-story in design, and form a "liner" or "wrap" around the parking ramps, which enhances the streetscape with housing facades by hiding the parking structure. The 116 townhomes, developed by Coral, will be

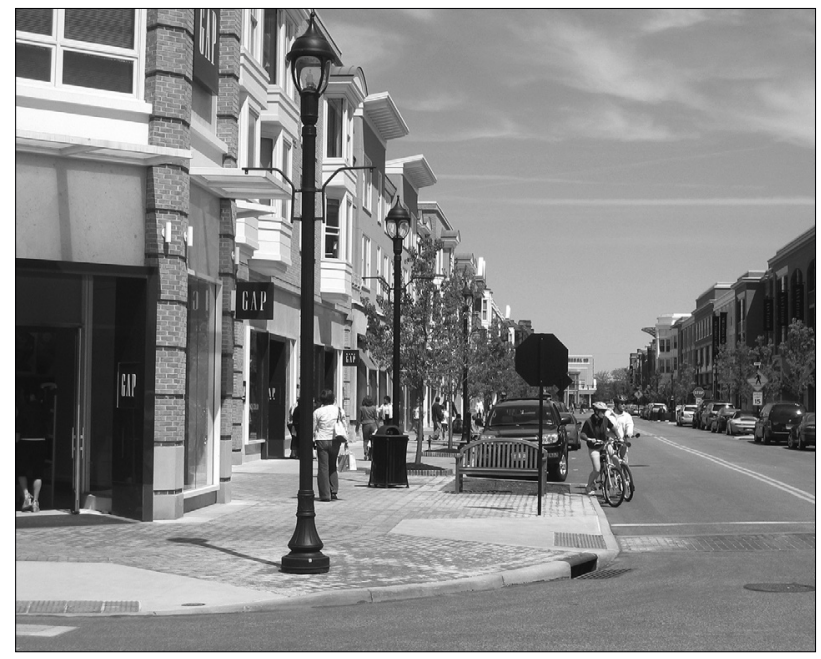

Figure 6

Pedestrians and bicyclists can easily navigate the streets of Crocker Park, assisted by trafffic-calming solutions. Bulbouts at intersections also serve as gathering areas, where benches provide places to rest and people-watch.

3 Bob Perry, Director of Planning and Economic Development (City of Westlake, Ohio). 2006, June 13. Interview with Colin Drukker, The Planning Center and Sam Newberg, Joe Urban, Inc. complicated elements of community. It is an acknowledgement that that more goes into community building than the creation of single-family homes or front porches. Above all else, the five steps model recognizes that each project must apply the steps in an appropriate and context-sensitive way. There is no one-size-fits-all solution and to create true community we must understand the unique economic, environmental, physical, social, and governmental components of each community.

\section{References}

Drukker, Colin. 2006. Five Steps Towards a New Suburbia. Costa Mesa, Ca. The Planning Center.

Galatas, Roger with Barlow, Jim. 2004. The Woodlands: The Inside Story of Creating a Better Hometown. Washington. ULI Press.

Taxin, Amy. 2006, October 11. "A Modern Solution for an Old Parking Problem". In The Orange County Register. 